\title{
NOTE ON TRANSCRIPTION
}

Hausa texts are rendered in the standard Nigerian orthography, but allowing for dialect variation where appropriate. A small number of special characters and particular pronunciations occur in the Hausa: $d / D$ and $6 / B$ represent glottalized stops; ' $y$ represents a glottalized glide; $k / K$ and $t s$ are ejectives; $c$ and $j$ represent alveopalatal affricates. Vowel length and tone have been marked only when they form the topic of discussion; in standard Nigerian orthography they are not marked.

\section{NOTE ON TEXTS AND TRANSLATIONS}

Depending upon available space, Hausa texts and English translations are sometimes laid out side by side and at other times sequentially. The provenance of the Hausa is given at the bottom of the column of Hausa text. Where both Hausa text and English translation are from a single source, then the provenance is given below the English text alone. Occasionally the English translation has been modified, and this is indicated by using the phrase 'adapted from'. Where a translation has been made by Sulaiman Ibrahim Katsina and myself working together, then the following attribution has been given: (GF \& SIK). Where no attribution is provided, the translation is by myself alone. 